\title{
Light Induced Regulation Pathway of Anthocyanin Biosynthesis in Plants
}

\author{
Yanyun Ma ${ }^{1,2}, \mathrm{Xu} \mathrm{Ma}^{1,2}$, Xiang Gao ${ }^{3}$, Weilin $\mathrm{Wu}^{4, *}$ and Bo Zhou ${ }^{1,2, *(D)}$ \\ 1 Key Laboratory of Saline-Alkali Vegetation Ecology Restoration, Northeast Forestry University, \\ Ministry of Education, Harbin 150040, China; myy060528@163.com (Y.M.); maxu990620@163.com (X.M.) \\ 2 College of Life Science, Northeast Forestry University, Harbin 150040, China \\ 3 Key Laboratory of Molecular Epigenetics of MOE and Institute of Genetics \& Cytology, \\ Northeast Normal University, Changchun 130024, China; gaox891@nenu.edu.cn \\ 4 Agricultural College, Yanbian University, Yanji 133002, China \\ * Correspondence: wlwu@ybu.edu.cn (W.W.); bozhou2003@163.com (B.Z.); Tel.: +86-183-4338-8262 (W.W.); \\ +86-0451-8219-1738 (B.Z.)
}

Citation: Ma, Y.; Ma, X.; Gao, X.; Wu, W.; Zhou, B. Light Induced Regulation Pathway of Anthocyanin Biosynthesis in Plants. Int. J. Mol. Sci. 2021, 22, 11116. https://doi.org/ 10.3390/ijms222011116

Academic Editor: Sun-Hyung Lim

Received: 20 September 2021

Accepted: 10 October 2021

Published: 15 October 2021

Publisher's Note: MDPI stays neutral with regard to jurisdictional claims in published maps and institutional affiliations.

Copyright: (c) 2021 by the authors. Licensee MDPI, Basel, Switzerland. This article is an open access article distributed under the terms and conditions of the Creative Commons Attribution (CC BY) license (https:// creativecommons.org/licenses/by/ $4.0 /)$.

\begin{abstract}
Anthocyanins are natural pigments with antioxidant effects that exist in various fruits and vegetables. The accumulation of anthocyanins is induced by environmental signals and regulated by transcription factors in plants. Numerous evidence has indicated that among the environmental factors, light is one of the most signal regulatory factors involved in the anthocyanin biosynthesis pathway. However, the signal transduction of light and molecular regulation of anthocyanin synthesis remains to be explored. Here, we focus on the research progress of signal transduction factors for positive and negative regulation in light-dependent and light-independent anthocyanin biosynthesis. In particular, we will discuss light-induced regulatory pathways and related specific regulators of anthocyanin biosynthesis in plants. In addition, an integrated regulatory network of anthocyanin biosynthesis controlled by transcription factors is discussed based on the significant progress.
\end{abstract}

Keywords: anthocyanin biosynthesis; transcription factors; environmental regulation; light signal; regulatory network

\section{Introduction}

Plant growth and development are greatly affected by the environment. Anthocyanin production is affected by various environmental factors such as light, low temperature, drought, and salinity [1-3]. Light is a particularly important environmental factor inducing anthocyanin accumulation in plants. Different types of anthocyanin are widely distributed in various plant tissues such as flowers, fruits, stems, leaves, and underground tubers [4]. The anthocyanin accumulation in these plant tissues is shown as light-dependent or light-independent biosynthesis. The different light quality and intensity are perceived by receptors or signal factors to transduce them into downstream transcription factors [5]. Next, metabolites are synthesized by enzymes encoded by structural genes that are regulated by transcription factors to respond to light. Anthocyanins belonging to the flavonoids are important secondary metabolites to adapt to harmful environmental stress in plants.

Anthocyanins are universal water-soluble flavonoid pigments that are responsible for the widest color of leaves, petals, fruits, seeds, stems, and tubers of plants (Liu et al., 2021) [6]. Moreover, they have been shown to play a beneficial role in the visual activity, cancer, heart disease, and age-related neurodegenerative disorders [7], although no effects or even a negative effect on health-related parameters have also been reported [6,8]. Anthocyanins consist of an anthocyanidin backbone with sugar and acyl conjugates while anthocyanidins are composed of two aromatic benzene rings and an oxygenated heterocycle $[9,10]$. Due to the number of hydroxyl groups and glycosyl groups in the rings, anthocyanins have potent antioxidant activity to scavenge free radicals and reactive oxygen 
species (ROS) during environmental stresses [6]. Therefore, anthocyanins have protective effects during plant development through absorbing excess UV light, preventing lipid peroxidation and suppressing the activity of ROS. Then, plants have evolved to the biosynthetic pathways of anthocyanins to resist various abiotic stresses including UV irradiation, drought, high salinity, and low temperature [11].

Recently, a great number of studies have revealed that anthocyanin accumulated when plants are under environmental stress. In Arabidopsis, the accumulation of photoprotective anthocyanin pigments is light-dependent [12], which improves salt resistance under salt stress [13]. In Chinese bayberry fruit, blue light can enhance anthocyanin accumulation and improve the commercial and nutritional value of Chinese bayberry fruit [14]. In addition, the anthocyanin of 'Red Globe' in grape is a typical light-dependent accumulation, whose anthocyanin synthesis in the berry skin is induced by light [15]. In red apples, anthocyanin biosynthesis is also regulated by the light-induced expression of MdMYB1 [16]. Moreover, abiotic stress-induced anthocyanin accumulation and UVR8 (UV RESISTANCE LOCUS 8) expression are also indicated to be light-dependent and both $\mathrm{H}_{2} \mathrm{O}_{2}$ and $\mathrm{NO}$ are involved in UV-B-induced anthocyanin accumulation in radish sprouts [17]. Next, the pathway of light induces signal factors to activate the transcription of anthocyanin biosynthesis genes to produce anthocyanins for stress tolerance is concluded. However, many signal transduction regulators and key transcription factors in the complicated anthocyanin biosynthesis regulatory network remain to be identified. To provide a detailed overview of the known molecular regulatory mechanisms of light-dependent and -independent anthocyanin biosynthesis in plants and provide a theoretical foundation for the application of colored photo-selective nets in the breeding of crops, fruits, and ornamental plant species, this review focuses on known physiological, biochemical, and molecular mechanisms involved in the light regulation of anthocyanin biosynthesis and their role in abiotic stress tolerance.

\section{Anthocyanins Accumulation in Plants}

In the natural environment, anthocyanins participate in the formation of multicolors in fruits, flowers, leaves, even roots of plants $[7,18]$. Different kinds of anthocyanins modified by methylation and hydroxylation at different positions of C6-C3-C6 carbon skeleton structures decide different colors varying from orange, red, and purple to blue in plants $[7,19]$ (Table 1). The physiological role of anthocyanin in plants consists of defending against viral, bacterial, and fungicidal activities, absorbing excess visible and UV light irradiance, attracting pollinators and seed dispersers, and scavenging excess ROS under abiotic stresses $[6,11,20]$. Anthocyanins are synthesized in the endoplasmic reticulum and transported to accumulate in the vacuoles of a wide range of cells and tissues in both the vegetative and reproductive organs of plants [20]. The synthesis of anthocyanins in plants is controlled by structural genes and can be divided into four stages [21,22]. The early stage is from phenylalanine to 4-coumaryl CoA sequentially catalyzed by phenylalanine ammonialyase (PAL), cinnamate 4-hydroxylase $(\mathrm{C} 4 \mathrm{H})$, and 4-coumarate-CoA ligase (4CL). Then, 4-coumaroyl CoA is converted to dihydrokaempferol (DHK), which is regulated by chalcone synthase (CHS), chalcone isomerase (CHI), and flavanone 3-hydroxylase (F3H). DHK can also be converted to dihydroquercetin (DHQ) by flavonoid $3^{\prime}$-hydroxylase $\left(\mathrm{F}^{\prime} \mathrm{H}\right)$ or catalyzed by flavonoid $3^{\prime} 5^{\prime}$-hydroxylase $\left(\mathrm{F}^{\prime} 5^{\prime} \mathrm{H}\right)$ to form dihydromyricetin. Next, $\mathrm{DHK}, \mathrm{DHQ}$, and dihydromyricetin are separately converted to leucopelargonidin, leucocyanidin, and leucodelphinidin by dihydroflavonol 4-reductase (DFR). Finally, these leucoanthocyanidins are catalyzed by anthocyanidin synthase/leucoanthocyanidin dioxygenase (ANS/LDOX) to form colored anthocyanidins (pelargonidin, cyanidin, delphinidin) [23]. Then, these anthocyanidins can be further modified by UDP-glucose flavonoid glucosyltransferase (UFGT), acetylase, O-methyltransferase (OMT), and anthocyanin transferase (AT) [24] to produce stable and water-soluble pigments (Figure 1). These flavonoid products vary in different plants due to the evolution of anthocyanin metabolism under environmental selective pressures [25]. Anthocyanins show potent antioxidant activities and are effective 
scavengers of ROS in vitro [26,27]. In addition, anthocyanins are involved in regulating ROS-induced signaling responding to environmental cues [28-30]. Anthocyanins may be regulators of the ROS-signaling network due to their ability to interact with protein and to enhance the activity of protein through the ROS reaction [20,31,32]. However, the functional roles of flavonoids in plants remain indistinct not only for their numerous varieties, but also for their different influences in different plant species. According to different properties of solubility, light absorption, and distribution patterns in various parts of the plant, anthocyanins have been cataloged numerically [33], and the composition profile of anthocyanins varied under different stresses $[34,35]$. The biological functions of different types of anthocyanins still need to be identified in various plants. Moreover, the roles of family genes, encoded enzymes of the anthocyanin biosynthetic pathway, also need to be clarified [36-38].

Table 1. Chemical structure and physical characters of the six common anthocyanindins.

\begin{tabular}{|c|c|c|c|c|c|}
\hline \multirow{2}{*}{ Chemical Structure } & \multicolumn{2}{|c|}{ Substitution } & \multirow{2}{*}{$\begin{array}{c}\text { Anthocyanidin } \\
\text { Name }\end{array}$} & \multirow{2}{*}{ Color } & \multirow{2}{*}{$\begin{array}{c}\lambda \text { max in the } \\
\text { Visible Spectrum }\end{array}$} \\
\hline & R1 & R2 & & & \\
\hline \multirow{6}{*}{ 10 } & $\mathrm{H}$ & $\mathrm{H}$ & $\begin{array}{l}\text { Pelargonidin } \\
\text { (Pg) }\end{array}$ & Orange & $494 \mathrm{~nm}$ \\
\hline & $\mathrm{OH}$ & $\mathrm{H}$ & Cyanidin (Cy) & Orange-red & $504 \mathrm{~nm}$ \\
\hline & $\mathrm{OH}$ & $\mathrm{OH}$ & $\begin{array}{l}\text { Delphinidin } \\
\text { (Dp) }\end{array}$ & Blue-red & $508 \mathrm{~nm}$ \\
\hline & OCH3 & $\mathrm{H}$ & Peonidin (Pn) & Orange-red & $506 \mathrm{~nm}$ \\
\hline & $\mathrm{OCH} 3$ & $\mathrm{OH}$ & Petunidin $(\mathrm{Pt})$ & Blue-Red & $508 \mathrm{~nm}$ \\
\hline & $\mathrm{OCH} 3$ & $\mathrm{OCH} 3$ & Malvidin (Mv) & Blue-red & $510 \mathrm{~nm}$ \\
\hline
\end{tabular}

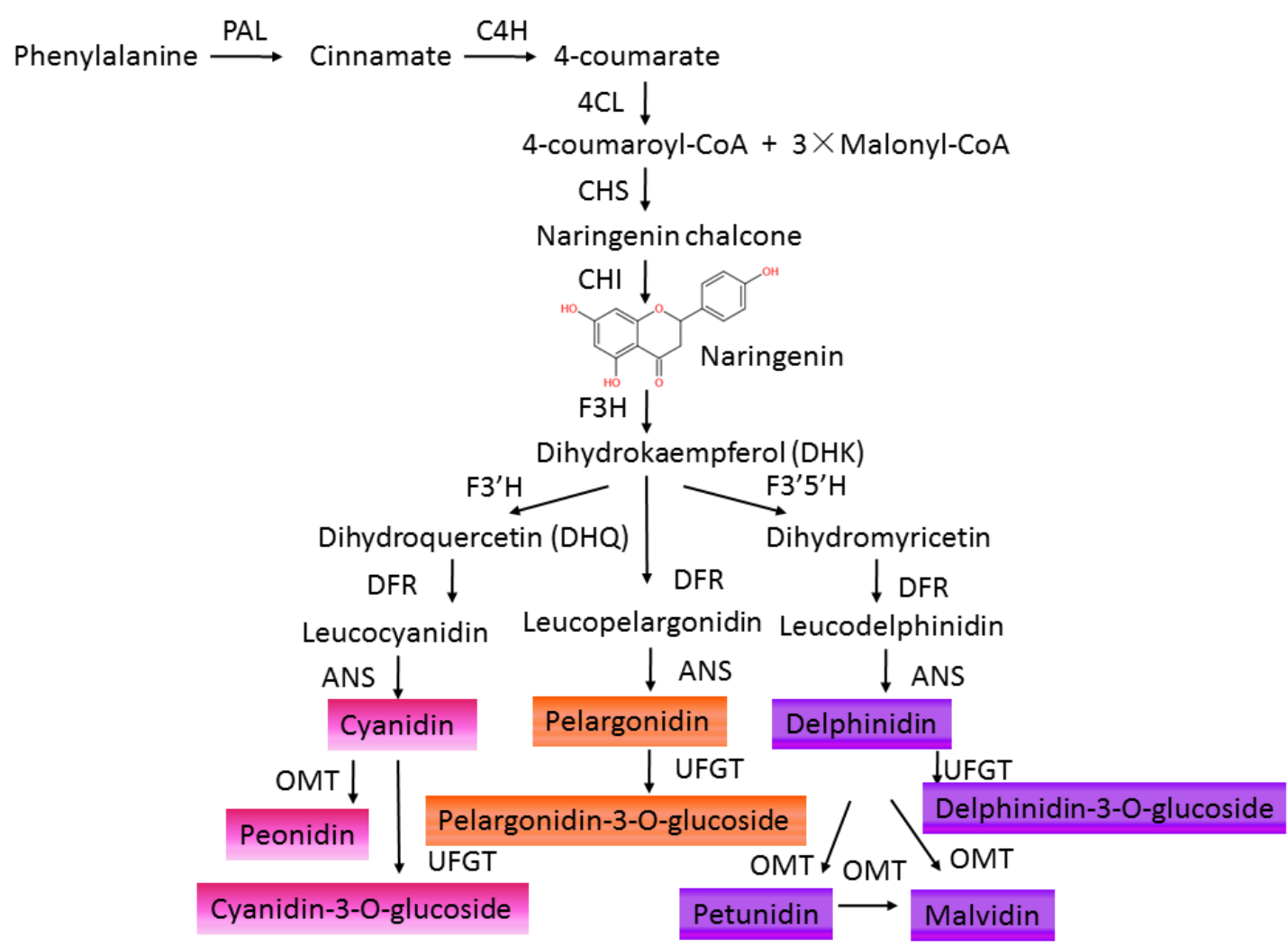

Figure 1. The pathway of anthocyanin biosynthesis. PAL, phenylalanine ammonia lyase; $\mathrm{C} 4 \mathrm{H}$, cinnamate 4-hydroxylase; 4CL, 4-coumarate CoA ligase; $\mathrm{CHS}$, chalcone synthase; $\mathrm{CHI}$, chalcone isomerase; $\mathrm{F} 3 \mathrm{H}$, flavanone 3-hydroxylase; $\mathrm{F}^{\prime}{ }^{\prime} \mathrm{H}$, flavonoid 30 hydroxylase; F3'5' H, flavonoid 3050hydroxylase; FLS, flavonol synthase; DFR, dihydroflavonol 4-reductase; ANS, anthocyanidin synthase; UFGT, UDP-galactose flavonoid 3-O-galactosyltransferase; OMT, O-methyl transferase. 


\section{Regulatory Pathway of Anthocyanin Biosynthesis}

3.1. Regulatory Factors Involved in Anthocyanin Biosynthesis

According to the research of Arabidopsis, it is well known that early anthocyanin biosynthetic genes (CHS, CHI, F3H, F3' H, and FLS) are regulated by R2R3-MYB transcription factors MYB11, MYB12, MYB111, and MYB75 while the late biosynthetic genes (DFR, ANS/LDOX, UFGT) are regulated by the MBW complex (R2R3-MYBs such as MYB75, MYB90, MYB113, and MYB114, bHLH, and WD40) [39-41]. In addition to MYBbHLH-WDR transcription factors, other regulatory proteins have also been identified to be involved in anthocyanin biosynthesis in plants including members of the NAC transcription family [42,43], MADS-box proteins [44-46], bZIP transcription factors [47-49], WRKY transcription factors [50], and SPL transcription factors [51,52]. These transcription factors take positive or negative roles in regulating the expression of structural anthocyanin biosynthesis genes and determine the anthocyanin accumulation in developmental and environmental regulation.

\subsection{The Activation of Positive R2R3-MYB Factors Is Sufficient for Promoting Anthocyanin Biosynthesis}

Among these transcription factors, MYB transcription factors play a significant role in regulating anthocyanin biosynthesis. Many anthocyanin-related R2R3-MYB factors have been identified from many plants such as Arabidopsis [39], grape [53], Gerbera [54], eggplant [55], tomato [55], populous [56], apple [57,58], etc. Most of these are R2R3-MYB proteins with the motif [D/E]LX2[R/K]X3LX6LX3R in the R3 domain, which is necessary to interact with bHLH acting as activators to increase anthocyanin accumulation [59]. In Arabidopsis, MYB75 (PAP1), MYB90 (PAP2), MYB113 (PAP3), and MYB114 (PAP4) show very high conserved sequences, and their overexpression increases the accumulation of anthocyanin through TTG1- and bHLH-dependent regulating late anthocyanin pathway genes [39]. In addition, the transcription level of PAP1 is higher than that of the other three MYB genes in young seedlings of Arabidopsis. In AtMYB75 transgenic tomato plants, anthocyanin production was also induced in tomato plants [60]. Moreover, overexpressing a single SIMYB75 TF can lead to abundant anthocyanin accumulation in both vegetative and reproductive organs of tomatoes [61] and another MYB TF SIAN2-like was also identified to be responsible for the Aft phenotype (anthocyanin fruit). In blueberry, VcMYBL1 has been identified to interact with VcbHLHL1 to promote anthocyanin biosynthesis [62]. In apple, MdMYB3 is also characterized to activate transcriptional flavonoid pathway genes and regulate the accumulation of anthocyanin in the skin of apple fruits [63]. SmMYB1 isolated in eggplant can interact with a heterologous bHLH, but the C-terminal domain in SmMYB1 is essential for transcriptional activation of anthocyanin genes [64].

\subsection{The Varieties of R2R3 MYBs Determine the Regulatory Specificity of Anthocyanin Accumulation}

These R2R3 MYBs have conserved R2R3 domain sequences, which determine anthocyanin pathway specificity. For example, in Arabidopsis, PAP4 activates the transcription of UFGT, which can produce anthocyanins from anthocyanidins, while TT2 regulates the expression of $A N R$, which is specific to proanthocyanin biosynthesis [65]. Alteration of individual amino acids of the R2R3 domain in PAP4 and TT2 can lead to changes in activation of the ANR and UFGT promoter. The amino-acid change in TT2 (Gly $39 \rightarrow \mathrm{Arg}$ ) can switch TT2 specificity toward the anthocyanin pathway while the amino-acid mutant $\left(\mathrm{Arg}^{39} \rightarrow\right.$ Gly) and exchange of motif (Ala-Asn-Asp-Val $\rightarrow$ Asp-Asn-Glu-Ile ${ }^{90-93}$ ) in PAP4 switches PAP4 specificity toward the PA pathway [65]. The orthologs VvMYBA2 and VvMYBPA2 in grapevine also have similar amino acids for pathway specificity [65]. Therefore, the anthocyanin pathway specificity is determined by the amino acid composition of the R2R3 domain in MYB transcription factors and the cis-elements in the promoters of anthocyanin biosynthetic genes. Due to the conservation of R2R3-MYB, regulatory differences are determined by promoter divergence rather than the divergence of the regulators $[65,66]$. Then, 
it is not difficult to understand that MYB transcription factors particularly regulate the expression of different anthocyanin pathway genes in various plants. In Arabidopsis, MYB11, MYB12, and MYB111 activate promoters of early genes (CHS, CHI, F3H, and FLS) but not of late genes $\left(F 3^{\prime} H\right.$ and $\left.D F R\right)[67,68]$. However, the expression of PAL1 and CHS remains unchanged in MYB75, MYB90, MYB113, and MYB114 RNAi seedlings, and the transcription for the late genes $D F R, F 3^{\prime} H, U G T 75 C 1, L D O X$, and GST12 is reduced [39]. In apple fruit, MdMYB114 also promotes anthocyanin accumulation by directly controlling the expression of late genes MdANS, MdUFGT, and MdGST [58], but in turnip (Brassica rapa), BrMYB75 can bind the promoter of early gene CHS to regulate anthocyanin biosynthesis [36]. Moreover, overexpression of MdMYB90-like in apple bud can induce the expression of both early and late genes including $M d C H S, M d C H I, M d A N S$, and MdUFGT [57]. In tomatoes, two anthocyanin-related R2R3-MYB factors take different tissue-specific regulatory roles in anthocyanin accumulation. One is SIAN2/SIMYB75, which is as a positive regulator of anthocyanin biosynthesis in vegetative tissues of tomato plants including hypocotyls, cotyledons, stems, and leaves [69], and the other is SlAN2-like/Aft, which determines anthocyanins in the fruits of tomato plants [70,71].

\subsection{The Negative MYB Proteins Repress Overexpression of Anthocyanin Biosynthetic Genes to Maintain the Balance of Pigment Accumulation}

In contrast, some $\mathrm{MYB}$ proteins play a negative role in regulating anthocyanin biosynthesis such as AtMYB4, AtMYB7, AtMYBL2, AtCPC in Arabidopsis [72,73], FaMYB1 in strawberry [74], VvMYBC2-L1 in grapevine [75], and SITRY, SIMYBATV in tomato [76,77]. AtMYB4 and AtMYB7, with the C-terminal EAR (ERF-associated amphiphilic repression) transcription repressor motif (with LxLxL or DLNxxP core sequence), repress the flavonoid biosynthesis by negatively regulating DFR and UGT gene expression [78], while AtMYBL2 with the C2 repressor motif (pdLNLD/ELxiG/S) can suppress the expression of DFR and TT8 to regulate anthocyanin biosynthesis [73]. Moreover, AtCPC, which is just like AtMYBL2 with single-repeat R3, acts as competitive inhibition of the MBW complex to negatively regulate the anthocyanin pathway in Arabidopsis [79]. In grape berry, the R2R3MYB protein VvMYBC2-L1 as AtMYB4 has also conserved the C2 motif in the C-terminal region and acts as a direct repressor to downregulate the expression of phenylpropanoid synthesis genes or as an indirect repressor to compete with MYB activator via binding affinity with the promoter of bHLH and WD40 [80]. The R2R3-MYB repressor FaMYB1 with the DNEV motif in strawberry is different to the AtMYB4 motif DNEI and the different motifs in the C-terminus of AtMYB4-like and FaMYB1-like repressors show potentially distinct mechanisms of action. SITRY, SIMYBATV in tomato such as AtCPC, and AtMYBL2 belong to single-repeat R3-MYB factors without a repressive motif, but they retain the motif responsible for binding to bHLH. The role of these MYB repressors in anthocyanin biosynthesis has been reviewed in detail [81,82]. Therefore, the regulation of MYB repressors and activators maintains the balance of accumulation of anthocyanin in plants, and MYB transcription factors are considered key components that provide specificity for the downstream genes and cause tissue-specific anthocyanin accumulation [83].

\subsection{Different bHLH Proteins Interact with MYB Factors to Form Specific MBW Complex}

As cofactors of MYB activators and repressors, bHLH proteins incorporating the MYB-interacting region, WD40/AD domain, basic helix-loop-helix domain, and ACT domain are responsible for MYB interaction and promoter binding of anthocyanin biosynthetic genes [84]. The bHLH family has been divided into 26 subfamilies [85] and the IIIf subfamily bHLH members are involved in both flavonoid biosynthesis and trichome formation [86]. The binding of the bHLH proteins with WD40 protein can be modulated by different R2R3 MYB proteins. In Arabidopsis, three bHLH TFs, GL3, EGL3, and TT8, have been shown to interact with R2R3-MYB proteins and regulate flavonoid biosynthesis [39,87]. AtTT8 can interact with AtTTG1 to form stable MBW complexes with different R2R3 MYBs while AtGL3 and AtEGL3 show competitive complex formation with some R2R3 MYBs [88]. The AtTTG1-bHLH interactions are modulated positively and negatively 
through the addition of R2R3 MYB proteins in Arabidopsis, [88]. PhAN1 and PhJAF13 in petunia have also been identified to be involved in anthocyanin $[89,90]$. In Solanaceous plants, AN1 directly regulates the expression of biosynthetic genes, whereas JAF13 can regulate the transcription of AN1 [91]. Then, the IIIf subfamily bHLHs can also be further divided into JAF13 clade and AN1 clade [90]. In the petunia hybrid, the interaction of PhAN1 with PhAN11 is promoted by the addition of the phAN4 R2R3 MYB protein, while the interaction of PhJAF13 with PhAN11 is significantly reduced in the presence of R2R3 MYB proteins [88]. Therefore, in different species, even in different tissues of the same plant, the functions of the bHLHs and MBW complexes vary. For example, AcMYB123 and AcbHLH42 can activate the function of the promoters of AcF3GT1 and AcANS and be involved in the spatiotemporal regulation of anthocyanin biosynthesis, specifically in the inner pericarp of kiwifruit [92]. MdbHLH3 can also bind to the promoters of MdDFR, MdUFGT, and MdMYB1 to activate their expression, which is involved in anthocyanin biosynthesis in apples. The individual combinations of bHLH and R2R3 MYB proteins regulate the expression of different anthocyanin synthetic genes and determine the spatiotemporal pigment accumulation in plants.

\subsection{WD40 Protein, the Stabilizer of MBW Complex}

The WD40 protein has 4-10 random WD repeat domains, which consist of 40 amino acid sequences ending in tryptophan (W) and aspartic acid (D). In Arabidopsis, AtTTG1, a member of the WD 40 proteins, is related to seedling anthocyanin accumulation and seed coat pigmentation [93]. AtTTG1-GL3/EGL3/TT8-TT2/MYB5 complexes are responsible for seed while AtTTG1-GL3/EGL3/TT8-PAP are relevant in vegetative tissue [94,95]. MdTTG1, the WD40 protein in apple, can interact with MdbHLH3 and MdMYB9 to control the expression of downstream structural genes [96]. Among the MBW complexes, WD40, which is involved in stabilizing the MBW complex, is generally similar between anthocyanin-pigmented and non-pigmented tissues [97,98].

\subsection{Other Regulation Proteins beyond MBW Complex}

In addition to the MBW complex, the NAC, MADS, bZIP, WRKY, SPL transcription factors are also involved in the regulation of anthocyanin biosynthesis. A NAC transcription factor, MdNAC42, can interact with MdMYB10 to positively regulate anthocyanin accumulation in red-fleshed apples [43]. Moreover, MdHY5, a bZIP protein, promotes anthocyanin biosynthesis by positively regulating its own transcription and that of MdMYB10 and even downstream anthocyanin biosynthesis genes through binding to E-box and G-box motifs in apple [49]. MdHY5 can also promote the expression of MdNAC52, which regulates the expression of MdMYB9 and MdMYB11 to increase anthocyanin biosynthesis [46]. Another MdbZIP44, an ABA-induced bZIP transcription factor, can interact with MdMYB1 to enhance the binding of MdMYB1 to its downstream genes and promote anthocyanin accumulation [47]. MdWRKY40, a wounding-responsive protein in apple, has also been identified to interact with MdMYB1 and enhance the binding of MdMYB1 to its target genes for anthocyanin biosynthesis [99]. In Arabidopsis, a WRKY TF TTG2 can interact with the WD-repeat protein TTG1 in the MBW complex to form a four-component complex involved in the PA pathway $[100,101]$. However, AtWRKY41 represses anthocyanin accumulation by negatively regulating the expression of AtMYB75, AtMYB111, and AtMYBD in Arabidopsis [50]. As in apple, MdWRKY41 is negatively regulated by MdHY5, which weakens the effect of the MdWRKY41-MdMYB16 repressor on anthocyanin accumulation [102]. To VmTDR4, the MADS-box protein in bilberry regulates the accumulation of anthocyanins through direct or indirect control of R2R3 MYB transcription factors [45]. In addition, the FcMADS9 protein in fig promotes anthocyanin accumulation, and ethylene has been proven to be involved in its regulation [103]. Furthermore, the coloration regulation of SIMADS-RIN in tomato and MdMADS1 in apple is related to ethylene, which suggests a link between MADS-box transcription factors regulating anthocyanin accumulation and ethylene [104-106]. Conversely, SQUAMOSA PROMOTER BINDING PROTEIN-LIKE 
(SPL) genes targeted by miR156, take a negative role in anthocyanin accumulation through destabilization of an MYB-bHLH-WD40 transcriptional activation complex [52]. In a word, a large number of anthocyanin activators and repressors have been confirmed to be involved in regulating the expression of anthocyanin biosynthetic gene components and the stabilization of the MBW complex. Therefore, anthocyanin biosynthesis is positively or negatively regulated by multi-transcription factors through interacting with the MBW complex or directly binding to the promoters of anthocyanin biosynthetic genes (Figure 2).

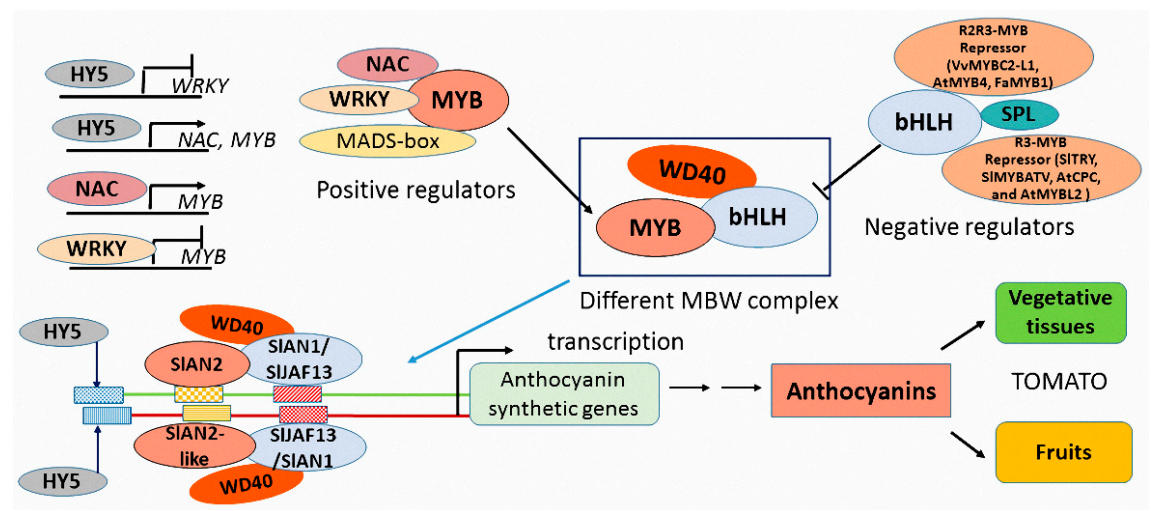

Figure 2. The regulatory pathway of anthocyanin biosynthesis in plants. NAC, WRKY, MADS-box can interact with MYB to form BMW complex and positively regulate the expression of anthocyanin synthetic genes. In the regulatory pathway, the expression of NAC, MYB is regulated by HY5, NAC, and WRKY, and the expression of WRKY is also regulated by HY5. However, some negative regulators such as VvMYBC2-L1, AtMYB4, FaMYB1 belonging to R2R3-MYBs, SITRY, SIMYBATV, AtCPC, and AtMYBL2 belonging to R3-MYBs interact with bHLH to compete with MYB and disturb the MBW complex. Another negative regulator SPL can also interact with bHLH to affect MYB-bHLH-WD40 complex. The transcription factor HY5 and MBW complex which consists of different MYB proteins such as SIAN2 and SIAN2-like and bHLH proteins such as SIAN1 and SIJAF13 in tomato can bind to the promoters of different anthocyanin synthetic genes to activate their transcription and accumulate anthocyanin in specific vegetative tissue or fruits.

\section{Light Induced Anthocyanin Accumulation in Plants}

\subsection{Light Receptor and Light Signal Transduction}

Light is essential for plant growth and development, but excess high-energy UV irradiance can cause damage to a cell, and anthocyanin accumulation in plants benefits plants in enhancing resistance to UV stress [20,107]. Plants have developed sophisticated photoreceptor systems such as phytochromes (red/far-red photoreceptors), cryptochromes, and phototropin (blue/UV-A photoreceptors) and UVR8 (UV-B photoreceptors) to adapt to variable light radiation [108]. Many plants accumulate anthocyanin in a light-dependent manner, that is, anthocyanin biosynthesis of these species is light induction. For example, the anthocyanin accumulation in fruits such as tomato [70], apple $[16,109,110]$, pear (Pyrus pyrifolia) [111,112], lychee (Litchi chinensis) [113], and grape (Vitis vinifera) [114]. Photoreceptors sense the different light environments and bring about structural change or modification of the receptor protein. Then, the activated receptor proteins transfer to the nucleus and interact with positive transcription factors or inactivate a master negative regulator COP1 to regulate the expression of downstream genes [108].

Phytochromes have been reported to perceive a high red/far-red ratio to convert from the Pr to Pfr isoform, and the active Pfr form can interact with PIFs to regulate light-regulated gene expression. In addition, activated phytochromes can rearrange the COP1-SPA complex to make it non-functional or inactivate the COP1-SPA E3 ligase to avoid the degradation of positive transcription factors such as HY5 [115-117]. Moreover, the photoactivated cryptochrome oligomers interact with cryptochrome-interacting proteins such as COP1, CIB, SPA, BIC, PIF, PPK, AUX/IAA, AGB, and phytochrome to form a cryptochrome complexome mediating blue-light regulation of transcription or protein 
stability [118]. The CRY-COP1-SPA interaction positively regulates the abundance of the HY5 protein [119]. For the UV-B receptor, UVR8 protein absorbing UV-B light causes the UVR8 dimer to break and the resulting monomer migrates into the nucleus to interact with COP1 and form UVR8-COP1-SPA complexes [120-122]. The UVR8-COP1-SPA interaction also results in the stabilization of HY5 to initiate UV-B mediated gene expression. Natural UV light intensities and high temperatures have been reported to induce increased acylation levels of anthocyanidin (the delphinidin and petunidin derivatives) in Vitis vinifera [123], and the flavonol and anthocyanin accumulation is also impacted in the treatment of light quality / quantity (UV-B) and temperatures during the berry development of grape [124]. This implies that different light quality/quantity can affect the activity of anthocyanin biosynthetic genes to produce different anthocyanidin derivatives that are also regulated by other abiotic factors such as temperature and drought [125].

\subsection{Light Signal Transduction Factor HY5}

HY5, which is unstable in darkness and is degraded by COP1 via the $26 \mathrm{~S}$ proteasome pathway or is light stable through SPA by dissociating with COP1 [126], has been identified to act as a master regulator of light signal transduction and directly activate the expression of anthocyanin biosynthesis and regulatory genes including MdMYB1 in apple [49] and AtPAP1/MYB75 in Arabidopsis [127]. HY5 can bind the T/G-box (CACGTT), E-box (CAATTG), GATA-box (GATGATA), ACE-box (ACGT), Z-box (ATACGGT), and C-box (GTCANN) as well as the hybrid C/G- (G) and C/A-boxes in the promoters of many genes that are involved in light signaling [128] and anthocyanin biosynthesis [127]. In tomatoes, the light-responsive SIAN2-like can activate the expression of both anthocyanin biosynthetic genes and their regulatory genes to accumulate anthocyanin. However, if a functional SIAN2-like gene is driven by the fruit-specific promoter in a tomato cultivar, the high-level anthocyanins will accumulate in both the peel and flesh with light-independent biosynthesis [70]. Then, a light signal is perceived by photoreceptors and transduced to HY5 and other regulated proteins to activate MYB transcription factors for light-dependent anthocyanin biosynthesis.

\subsection{HY5-Dependent and-Independent Pathway Regulate Light-Dependent and-Independent Anthocyanin Biosynthesis Separately}

However, when the MYB regulated proteins and anthocyanin biosynthetic genes are activated to express constitutively, the anthocyanin accumulation will display lightindependent biosynthesis. The research of light in regulating anthocyanin biosynthesis in dark-red and bicolored cherry cultivars showed that light is necessary for anthocyanin biosynthesis in bicolored cherries, but not in the dark-red fruits [129]. In blueberry (Vaccinium spp.), the UV-B treatment induces HY5 expression to upregulate VcMYBPA1 and downregulate $\mathrm{VcMYBC} 2$, then promotes the accumulation of anthocyanins in the green fruit stage. Whereas in the mature fruit stage, anthocyanin synthesis is inhibited by increased VcMYBC2 levels when exposed to UV-B light through the HY5-independent pathway [130]. The stage-dependent anthocyanin biosynthesis in UV-B exposed blueberry is coordinately balanced by the anthocyanin-related MYB activators and repressors. Then, the light-dependent anthocyanin biosynthesis is regulated by 'double-negative logic' [82], that is, anthocyanin accumulation is determined by light-induced nuclear export or inactivation of the repressor COP1-SPA complex [131], de-repressing the HY5, and activating the MBW complex and anthocyanin biosynthesis. Certainly, other protein factors such as B-box (BBX) proteins can also respond to light and interact with $\mathrm{HY} 5$ to regulate the transcription of anthocyanin biosynthetic genes. In red pears, both PpBBX16 and PpBBX18 can form the PpBBX-PpHY5 complex to activate the expression of $P p M Y B 10$ and regulate anthocyanin accumulation [111,132], but PpBBX21, a negative regulator, can hinder the formation of the PpBBX18-PpHY5 complex and repress anthocyanin biosynthesis [132]. Moreover, MdBBX22 promotes UV-B-induced anthocyanin biosynthesis by MdBBX22-MdHY5 interaction in apple, and the expression of $M d B T 2$ is suppressed by UV-B treatment which can degrade the MdBBX22 protein through the 26S proteasome pathway [133]. MdTCP46 
and MdMYB1 also play positive roles in anthocyanin biosynthesis induced by high light intensity, but under low light intensity, MdBT2 ubiquitinates and degrades the MdTCP46 (Teosinte branched1/cycloidea/proliferating transcription factor 46) and MdMYB1 proteins to repress anthocyanin biosynthesis [110]. Furthermore, blue light signal transduction module CRY-COP1-HY5 contributes to the anthocyanin biosynthesis induced by blue light in red pear, but red light does not affect anthocyanin accumulation [112]. However, in ripening bilberry fruits, blue and red light are effective in inducing anthocyanin and delphinidin accumulation via CRY2/COP1 and HY5 or ABA-signal transduction [134]. Red light, blue light, and red/blue compound light also induce the strawberry fruit coloration [135]. Therefore, light intensity and light quality can induce different signal transduction factors involved in light-dependent anthocyanin biosynthesis.

However, some potato, turnip, and sweet potato varieties accumulate pigments as underground tubers, and it is obvious that the regulation of light-independent anthocyanin biosynthesis in these tubers is disintegrated in the HY5-COP1 signaling pathway. In addition, candidate HY5-independent regulators have been identified to regulate anthocyanin biosynthesis in tomatoes [136], which broadens our understanding of light-dependent and -independent anthocyanin biosynthesis. In flesh-colored tubers of the potato, cells lose pigment production when purple cells are continuously subcultured, turning from purple to white. StMYBATV, an anthocyanin repressor, may contribute to stopping anthocyanin biosynthesis in potato cell culture. Moreover, the level of DNA methylation is also associated with reprogramming the metabolism of anthocyanins [137]. In Aft/Aft atv/atv tomato plants, SIMYBATV loses its function to compete with SIAN2-like to interact with SIJAF13, which makes SIAN2-like interact with SIJAF13 and SIAN11 to form an MBW complex to activate the expression of SIAN1 and SIAN11 in a HY5-independent manner. Then, SIAN2-like interacts with SIAN1 and SIAN11 to regulate the transcription of anthocyanin biosynthetic genes to accumulate pigments in fully purple-skinned tomatoes [71]. Briefly, light signals induce anthocyanin accumulation via the HY5-mediated expression of anthocyanin biosynthetic genes. However, the regulation of light-independent anthocyanin biosynthesis is due to protein factors located upstream of the anthocyanin biosynthesis pathway to activate the expression of the MYB transcription factor and MBW components. The protein factors might be loss-functional repressors or HY5-independent activators (Figure 3).

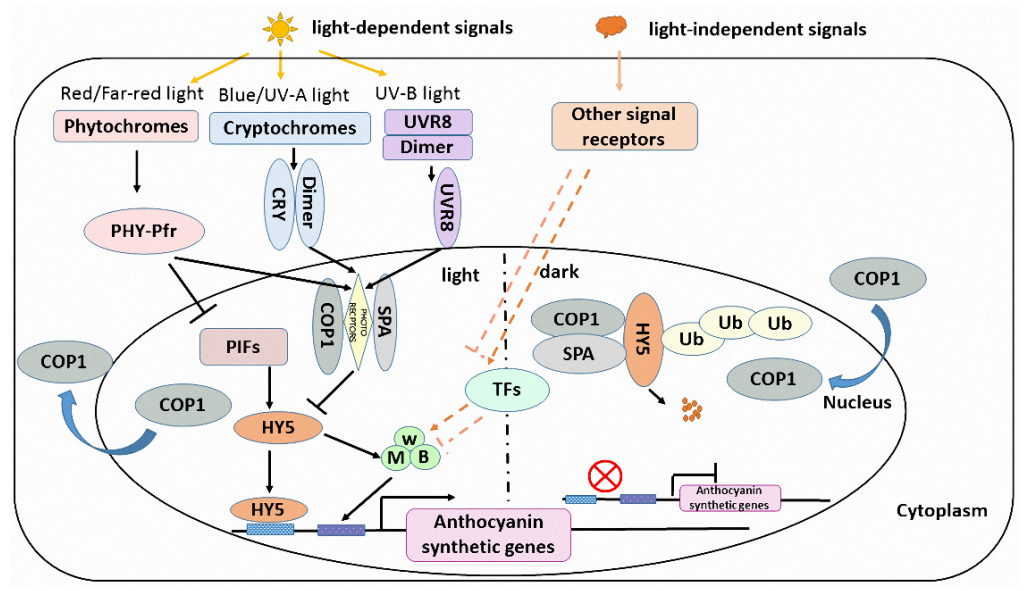

Figure 3. A simplified model of light-dependent and -independent regulation of anthocyanin biosynthesis in plants. During light-dependent anthocyanin biosynthesis, photoreceptors sense different wavelengths of light and are activated to be transferred into the nucleus, then the HY5COP1-SPA complex is rearranged to dissociate HY5 protein and to avoid the degradation of HY5 transcription factors. HY5 positively regulates the expression of anthocyanin biosynthetic genes and lead to pigment accumulation. During light-independent anthocyanin biosynthesis, positive or negative transcription factors are activated or suppressed to form an MBW complex regulating the expression of anthocyanin biosynthetic genes. 


\section{Conclusions and Perspectives}

Although much is now known about the regulatory pathway of anthocyanin biosynthesis, the functions of protein factors involved in anthocyanin accumulation in plants continue to be explored. In addition to the roles of the MBW complex and anthocyanin biosynthetic genes that determine spatial and temporal-specific pigmentation, there are other signal regulatory factors that respond to the environmental and developmental signals to activate the anthocyanin biosynthetic pathway. The specific mechanism by which anthocyanin can form in a light-dependent and -independent manner needs to be elucidated. Similarly, the signal factors related to abiotic stress such as low temperature, drought, and salinity-induced anthocyanin biosynthesis also remain to be identified. Moreover, epigenetic regulation, especially the methylation of protein-coding genes related to anthocyanin production in plants is still in its infancy. In addition, an integrated regulatory network of anthocyanin biosynthesis controlled by transcription factors of development and abiotic-response factors needs to be further explored. Overall, with the research progress of genetics and molecular biology, a clearer understanding of the mechanism of anthocyanin biosynthesis and accumulation will be obtained and provide a theoretical and practical basis for crop breeding in the future.

Author Contributions: Y.M. and X.M. collected the literature and provided materials of the manuscript; X.G. amended the manuscript; B.Z. wrote the manuscript and took part in the literature collection. W.W. reviewed and edited the manuscript. All authors have read and agreed to the published version of the manuscript.

Funding: This research was supported by the Open Project of Key Laboratory of Saline-Alkali Vegetation Ecology Restoration, Ministry of Education (Northeast Forestry University); the Fundamental Research Funds for the Central Universities (2572020DY21); the Science and Technology Research Project of Jilin Provincial Department of Education (JJKH20210574KJ); and the Yanbian University Project (ydkhz [2020] No. 9).

Conflicts of Interest: The authors declare that they have no known competing financial interests or personal relationships that could have appeared to influence the work reported in this paper.

\section{References}

1. Kumar, A.A.; Mishra, P.; Kumari, K.; Panigrahi, K.C. Environmental stress influencing plant development and flowering. Front. Biosci. 2012, 4, 1315-1324. [CrossRef]

2. Chen, Z.H.; Soltis, D.E. Evolution of environmental stress responses in plants. Plant Cell Environ. 2020, 43, 2827-2831. [CrossRef]

3. Jaakola, L. New insights into the regulation of anthocyanin biosynthesis in fruits. Trends Plant Sci. 2013, 18, 477-483. [CrossRef]

4. Saigo, T.; Wang, T.; Watanabe, M.; Tohge, T. Diversity of anthocyanin and proanthocyanin biosynthesis in land plants. Curr. Opin. Plant Biol. 2020, 55, 93-99. [CrossRef]

5. Kong, S.G.; Okajima, K. Diverse photoreceptors and light responses in plants. J. Plant Res. 2016, 129, 111-114. [CrossRef] [PubMed]

6. Liu, Y.; Tikunov, Y.; Schouten, R.E.; Marcelis, L.F.M.; Visser, R.G.F.; Bovy, A. Anthocyanin Biosynthesis and Degradation Mechanisms in Solanaceous Vegetables: A Review. Front. Chem. 2018, 6, 52. [CrossRef]

7. Khoo, H.E.; Azlan, A.; Tang, S.T.; Lim, S.M. Anthocyanidins and anthocyanins: Colored pigments as food, pharmaceutical ingredients, and the potential health benefits. Food Nutr. Res. 2017, 61, 1361779. [CrossRef] [PubMed]

8. Smeriglio, A.; Barreca, D.; Bellocco, E.; Trombetta, D. Chemistry, Pharmacology and Health Benefits of Anthocyanins. Phytother. Res. 2016, 30, 1265-1286. [CrossRef] [PubMed]

9. Tanaka, Y.; Sasaki, N.; Ohmiya, A. Biosynthesis of plant pigments: Anthocyanins, betalains and carotenoids. Plant J. 2008, 54, 733-749. [CrossRef]

10. Stommel, J.R.; Lightbourn, G.J.; Winkel, B.S.; Griesbach, R.J. Transcription Factor Families Regulate the Anthocyanin Biosynthetic Pathway in Capsicum annuum. J. Am. Soc. Hortic. Sci. 2009, 134, 244-251. [CrossRef]

11. Naing, A.H.; Kim, C.K. Abiotic stress-induced anthocyanins in plants: Their role in tolerance to abiotic stresses. Physiol. Plantarum 2021, 172, 1711-1723. [CrossRef]

12. Li, S.N.; Wang, W.Y.; Gao, J.L.; Yin, K.Q.; Wang, R.; Wang, C.C.; Petersen, M.; Mundy, J.; Qiu, J.L. MYB75 Phosphorylation by MPK4 Is Required for Light-Induced Anthocyanin Accumulation in Arabidopsis. Plant Cell 2016, 28, 2866-2883. [CrossRef]

13. Li, B.Z.; Fan, R.N.; Guo, S.Y.; Wang, P.T.; Zhu, X.H.; Fan, Y.T.; Chen, Y.X.; He, K.Y.; Kumar, A.; Shi, J.P.; et al. The Arabidopsis MYB transcription factor, MYB111 modulates salt responses by regulating flavonoid biosynthesis. Environ. Exp. Bot. 2019, $166,103807$. [CrossRef] 
14. Shi, L.Y.; Cao, S.F.; Chen, W.; Yang, Z.F. Blue light induced anthocyanin accumulation and expression of associated genes in Chinese bayberry fruit. Sci. Hortic. 2014, 179, 98-102. [CrossRef]

15. Sun, L.; Li, S.C.; Tang, X.P.; Fan, X.C.; Zhang, Y.; Jiang, J.F.; Liu, J.H.; Liu, C.H. Transcriptome analysis reveal the putative genes involved in light-induced anthocyanin accumulation in grape 'Red Globe' (V. vinifera L.). Gene 2020, 728, 144284. [CrossRef] [PubMed]

16. Takos, A.M.; Jaffe, F.W.; Jacob, S.R.; Bogs, J.; Robinson, S.P.; Walker, A.R. Light-induced expression of a MYB gene regulates anthocyanin biosynthesis in red apples. Plant Physiol. 2006, 142, 1216-1232. [CrossRef] [PubMed]

17. Wu, Q.; Su, N.N.; Zhang, X.Y.; Liu, Y.Y.; Cui, J.; Liang, Y.C. Hydrogen peroxide, nitric oxide and UV RESISTANCE LOCUS8 interact to mediate UV-B-induced anthocyanin biosynthesis in radish sprouts. Sci. Rep. 2016, 6, 29164. [CrossRef] [PubMed]

18. Mattioli, R.; Francioso, A.; Mosca, L.; Silva, P. Anthocyanins: A Comprehensive Review of Their Chemical Properties and Health Effects on Cardiovascular and Neurodegenerative Diseases. Molecules 2020, 25, 3809. [CrossRef] [PubMed]

19. Liu, H.; Liu, Z.; Wu, Y.; Zheng, L.; Zhang, G. Regulatory Mechanisms of Anthocyanin Biosynthesis in Apple and Pear. Int. J. Mol. Sci. 2021, 22, 8441. [CrossRef]

20. Landi, M.; Tattini, M.; Gould, K.S. Multiple functional roles of anthocyanins in plant-environment interactions. Environ. Exp. Bot. 2015, 119, 4-17. [CrossRef]

21. Kitamura, S.; Shikazono, N.; Tanaka, A. TRANSPARENT TESTA 19 is involved in the accumulation of both anthocyanins and proanthocyanidins in Arabidopsis. Plant J. 2004, 37, 104-114. [CrossRef] [PubMed]

22. Routaboul, J.M.; Dubos, C.; Beck, G.; Marquis, C.; Bidzinski, P.; Loudet, O.; Lepiniec, L. Metabolite profiling and quantitative genetics of natural variation for flavonoids in Arabidopsis. J. Exp. Bot. 2012, 63, 3749-3764. [CrossRef] [PubMed]

23. Chaves-Silva, S.; dos Santos, A.L.; Chalfun, A.; Zhao, J.; Peres, L.E.P.; Benedito, V.A. Understanding the genetic regulation of anthocyanin biosynthesis in plants-Tools for breeding purple varieties of fruits and vegetables. Phytochemistry 2018, 153, 11-27. [CrossRef] [PubMed]

24. Winkel-Shirley, B. Flavonoid biosynthesis. A colorful model for genetics, biochemistry, cell biology, and biotechnology. Plant Physiol. 2001, 126, 485-493. [CrossRef] [PubMed]

25. Serna, L.; Martin, C. Trichomes: Different regulatory networks lead to convergent structures. Trends Plant Sci. 2006, 11, 274-280. [CrossRef]

26. Ferreres, F.; Figueiredo, R.; Bettencourt, S.; Carqueijeiro, I.; Oliveira, J.; Gil-Izquierdo, A.; Pereira, D.M.; Valentao, P.; Andrade, P.B.; Duarte, P.; et al. Identification of phenolic compounds in isolated vacuoles of the medicinal plant Catharanthus roseus and their interaction with vacuolar class III peroxidase: $\mathrm{An}_{2} \mathrm{O}_{2}$ affair? J. Exp. Bot. 2011, 62, 2841-2854. [CrossRef]

27. Juadjur, A.; Mohn, C.; Schantz, M.; Baum, M.; Winterhalter, P.; Richling, E. Fractionation of an anthocyanin-rich bilberry extract and in vitro antioxidative activity testing. Food Chem. 2015, 167, 418-424. [CrossRef]

28. Heine, G.F.; Hernandez, J.M.; Grotewold, E. Two cysteines in plant R2R3 MYB domains participate in REDOX-dependent DNA binding. J. Biol. Chem. 2004, 279, 37878-37885. [CrossRef]

29. Taylor, L.P.; Grotewold, E. Flavonoids as developmental regulators. Curr. Opin. Plant Biol. 2005, 8, 317-323. [CrossRef]

30. Brunetti, C.; Di Ferdinando, M.; Fini, A.; Pollastri, S.; Tattini, M. Flavonoids as Antioxidants and Developmental Regulators: Relative Significance in Plants and Humans. Int. J. Mol. Sci. 2013, 14, 3540-3555. [CrossRef]

31. Payne, J.L.; Moore, J.H.; Wagner, A. Robustness, Evolvability, and the Logic of Genetic Regulation. Artif. Life 2014, 20, 111-126. [CrossRef] [PubMed]

32. Lin, Y.; Fan, L.; He, J.; Wang, Z.; Yin, Y.; Cheng, Y.; Li, Z. Anthocyanins contribute to fruit defense against postharvest green mold. Postharvest Biol. Technol. 2021, 181, 111661. [CrossRef]

33. Luo, J.; Nishiyama, Y.; Fuell, C.; Taguchi, G.; Elliott, K.; Hill, L.; Tanaka, Y.; Kitayama, M.; Yamazaki, M.; Bailey, P.; et al. Convergent evolution in the BAHD family of acyl transferases: Identification and characterization of anthocyanin acyl transferases from Arabidopsis thaliana. Plant J. 2007, 50, 678-695. [CrossRef] [PubMed]

34. Kovinich, N.; Kayanja, G.; Chanoca, A.; Riedl, K.; Otegui, M.S.; Grotewold, E. Not all anthocyanins are born equal: Distinct patterns induced by stress in Arabidopsis. Planta 2014, 240, 931-940. [CrossRef] [PubMed]

35. Kovinich, N.; Kayanja, G.; Chanoca, A.; Otegui, M.S.; Grotewold, E. Abiotic stresses induce different localizations of anthocyanins in Arabidopsis. Plant Signal. Behav. 2015, 10, e1027850. [CrossRef] [PubMed]

36. Zhou, B.; Wang, Y.; Zhan, Y.G.; Li, Y.H.; Kawabata, S. Chalcone Synthase Family Genes Have Redundant Roles in Anthocyanin Biosynthesis and in Response to Blue/Uv-a Light in Turnip (Brassica Rapa; Brassicaceae). Am. J. Bot. 2013, 100, $2458-2467$. [CrossRef] [PubMed]

37. Li, Z.; Vickrey, T.L.; McNally, M.G.; Sato, S.J.; Clemente, T.E.; Mower, J.P. Assessing Anthocyanin Biosynthesis in Solanaceae as a Model Pathway for Secondary Metabolism. Genes 2019, 10, 559. [CrossRef]

38. Wu, X.X.; Zhang, S.M.; Liu, X.H.; Shang, J.; Zhang, A.D.; Zhu, Z.W.; Zha, D.S. Chalcone synthase (CHS) family members analysis from eggplant (Solanum melongena L.) in the flavonoid biosynthetic pathway and expression patterns in response to heat stress. PLOS ONE 2020, 15, e0226537.

39. Gonzalez, A.; Zhao, M.; Leavitt, J.M.; Lloyd, A.M. Regulation of the anthocyanin biosynthetic pathway by the TTG1/bHLH/Myb transcriptional complex in Arabidopsis seedlings. Plant J. 2008, 53, 814-827. [CrossRef]

40. Dubos, C.; Stracke, R.; Grotewold, E.; Weisshaar, B.; Martin, C.; Lepiniec, L. MYB transcription factors in Arabidopsis. Trends Plant Sci. 2010, 15, 573-581. [CrossRef] 
41. Xu, W.; Dubos, C.; Lepiniec, L. Transcriptional control of flavonoid biosynthesis by MYB-bHLH-WDR complexes. Trends Plant Sci. 2015, 20, 176-185. [CrossRef]

42. Wang, J.F.; Lian, W.R.; Cao, Y.Y.; Wang, X.Y.; Wang, G.L.; Qi, C.D.; Liu, L.; Qin, S.J.; Yuan, X.W.; Li, X.S.; et al. Overexpression of BoNAC019, a NAC transcription factor from Brassica oleracea, negatively regulates the dehydration response and anthocyanin biosynthesis in Arabidopsis. Sci. Rep. 2018, 8, 13349. [CrossRef] [PubMed]

43. Zhang, S.; Chen, Y.; Zhao, L.; Li, C.; Yu, J.; Li, T.; Yang, W.; Zhang, S.; Su, H.; Wang, L. A novel NAC transcription factor, MdNAC42, regulates anthocyanin accumulation in red-fleshed apple by interacting with MdMYB10. Tree Physiol. 2020, 40, 413-423. [CrossRef]

44. Wang, R.Z.; Ming, M.L.; Li, J.M.; Shi, D.Q.; Qiao, X.; Li, L.T.; Zhang, S.L.; Wu, J. Genome-wide identification of the MADSbox transcription factor family in pear (Pyrus bretschneideri) reveals evolution and functional divergence. Peerj 2017, 5, e3776. [CrossRef] [PubMed]

45. Jaakola, L.; Poole, M.; Jones, M.O.; Kamarainen-Karppinen, T.; Koskimaki, J.J.; Hohtola, A.; Haggman, H.; Fraser, P.D.; Manning, K.; King, G.J.; et al. A SQUAMOSA MADS box gene involved in the regulation of anthocyanin accumulation in bilberry fruits. Plant Physiol. 2010, 153, 1619-1629. [CrossRef]

46. Sun, Q.; Jiang, S.; Zhang, T.; Xu, H.; Fang, H.; Zhang, J.; Su, M.; Wang, Y.; Zhang, Z.; Wang, N.; et al. Apple NAC transcription factor MdNAC52 regulates biosynthesis of anthocyanin and proanthocyanidin through MdMYB9 and MdMYB11. Plant Sci. 2019, 289, 110286. [CrossRef] [PubMed]

47. An, J.P.; Yao, J.F.; Xu, R.R.; You, C.X.; Wang, X.F.; Hao, Y.J. Apple bZIP transcription factor MdbZIP44 regulates abscisic acid-promoted anthocyanin accumulation. Plant Cell Environ. 2018, 41, 2678-2692. [CrossRef]

48. Liu, C.C.; Chi, C.; Jin, L.J.; Zhu, J.; Yu, J.Q.; Zhou, Y.H. The bZip transcription factor HY5 mediates CRY1a-induced anthocyanin biosynthesis in tomato. Plant Cell Environ. 2018, 41, 1762-1775. [CrossRef] [PubMed]

49. An, J.P.; Qu, F.J.; Yao, J.F.; Wang, X.N.; You, C.X.; Wang, X.F.; Hao, Y.J. The bZIP transcription factor MdHY5 regulates anthocyanin accumulation and nitrate assimilation in apple. Hortic. Res. 2017, 4, 17023. [CrossRef]

50. Duan, S.; Wang, J.; Gao, C.; Jin, C.; Li, D.; Peng, D.; Du, G.; Li, Y.; Chen, M. Functional characterization of a heterologously expressed Brassica napus WRKY41-1 transcription factor in regulating anthocyanin biosynthesis in Arabidopsis thaliana. Plant Sci. 2018, 268, 47-53. [CrossRef]

51. Chen, R.; Cao, Y.; Wang, W.T.; Li, Y.H.; Wang, D.H.; Wang, S.Q.; Cao, X.Y. Transcription factor SmSPL7 promotes anthocyanin accumulation and negatively regulates phenolic acid biosynthesis in Salvia miltiorrhiza. Plant Sci. 2021, 310, 110993. [CrossRef]

52. Gou, J.Y.; Felippes, F.F.; Liu, C.J.; Weigel, D.; Wang, J.W. Negative regulation of anthocyanin biosynthesis in Arabidopsis by a miR156-targeted SPL transcription factor. Plant Cell 2011, 23, 1512-1522. [CrossRef] [PubMed]

53. Xie, S.; Lei, Y.J.; Chen, H.W.; Li, J.N.; Chen, H.Z.; Zhang, Z.W. R2R3-MYB Transcription Factors Regulate Anthocyanin Biosynthesis in Grapevine Vegetative Tissues. Front. Plant Sci. 2020, 11, 527. [CrossRef]

54. Zhong, C.M.; Tang, Y.; Pang, B.; Li, X.K.; Yang, Y.P.; Deng, J.; Feng, C.Y.; Li, L.F.; Ren, G.P.; Wang, Y.Q.; et al. The R2R3-MYB transcription factor GhMYB1a regulates flavonol and anthocyanin accumulation in Gerbera hybrida. Hortic. Res. 2020, 7, 78. [CrossRef] [PubMed]

55. Shi, S.L.; Liu, Y.; He, Y.J.; Li, L.Z.; Li, D.L.; Chen, H.Y. R2R3-MYB transcription factor SmMYB75 promotes anthocyanin biosynthesis in eggplant (Solanum melongena L.). Sci. Hortic. 2021, 282, 110020. [CrossRef]

56. Wang, L.J.; Lu, W.X.; Ran, L.Y.; Dou, L.W.; Yao, S.; Hu, J.; Fan, D.; Li, C.F.; Luo, K.M. R2R3-MYB transcription factor MYB6 promotes anthocyanin and proanthocyanidin biosynthesis but inhibits secondary cell wall formation in Populus tomentosa. Plant J. 2019, 99, 733-751. [CrossRef]

57. Sun, C.; Wang, C.M.; Zhang, W.; Liu, S.A.; Wang, W.Y.; Yu, X.Y.; Song, T.; Yu, M.W.; Yu, W.C.; Qu, S.C. The R2R3-type MYB transcription factor MdMYB90-like is responsible for the enhanced skin color of an apple bud sport mutant. Hortic. Res. 2021, 8, 156. [CrossRef]

58. Jiang, S.H.; Sun, Q.G.; Zhang, T.L.; Liu, W.J.; Wang, N.; Chen, X.S. MdMYB114 regulates anthocyanin biosynthesis and functions downstream of MdbZIP4-like in apple fruit. J. Plant Physiol. 2021, 257, 153353. [CrossRef]

59. Zimmermann, I.M.; Heim, M.A.; Weisshaar, B.; Uhrig, J.F. Comprehensive identification of Arabidopsis thaliana MYB transcription factors interacting with R/B-like BHLH proteins. Plant J. 2004, 40, 22-34. [CrossRef]

60. Zuluaga, D.L.; Gonzali, S.; Loreti, E.; Pucciariello, C.; Degl'Innocenti, E.; Guidi, L.; Alpi, A.; Perata, P. Arabidopsis thaliana MYB75/PAP1 transcription factor induces anthocyanin production in transgenic tomato plants. Funct. Plant Biol. 2008, 35, 606-618. [CrossRef]

61. Jian, W.; Cao, H.H.; Yuan, S.; Liu, Y.D.; Lu, J.F.; Lu, W.; Li, N.; Wang, J.H.; Zou, J.; Tang, N.; et al. SIMYB75, an MYB-type transcription factor, promotes anthocyanin accumulation and enhances volatile aroma production in tomato fruits. Hortic. Res. 2019, 6, 22. [CrossRef]

62. Zhao, M.R.; Li, J.; Zhu, L.; Chang, P.; Li, L.L.; Zhang, L.Y. Identification and Characterization of MYB-bHLH-WD40 Regulatory Complex Members Controlling Anthocyanidin Biosynthesis in Blueberry Fruits Development. Genes 2019, 10, 496. [CrossRef]

63. Vimolmangkang, S.; Han, Y.P.; Wei, G.C.; Korban, S.S. An apple MYB transcription factor, MdMYB3, is involved in regulation of anthocyanin biosynthesis and flower development. BMC Plant Biol. 2013, 13, 176. [CrossRef] 
64. Docimo, T.; Francese, G.; Ruggiero, A.; Batelli, G.; De Palma, M.; Bassolino, L.; Toppino, L.; Rotino, G.L.; Mennella, G.; Tucci, M. Phenylpropanoids Accumulation in Eggplant Fruit: Characterization of Biosynthetic Genes and Regulation by a MYB Transcription Factor. Front. Plant Sci. 2015, 6, 1233. [CrossRef]

65. Heppel, S.C.; Jaffe, F.W.; Takos, A.M.; Schellmann, S.; Rausch, T.; Walker, A.R.; Bogs, J. Identification of key amino acids for the evolution of promoter target specificity of anthocyanin and proanthocyanidin regulating MYB factors. Plant Mol. Biol. 2013, 82, 457-471. [CrossRef]

66. Quattrocchio, F.; Wing, J.F.; van der Woude, K.; Mol, J.N.; Koes, R. Analysis of bHLH and MYB domain proteins: Species-specific regulatory differences are caused by divergent evolution of target anthocyanin genes. Plant J. 1998, 13, 475-488. [CrossRef] [PubMed]

67. Tan, H.; Man, C.; Xie, Y.; Yan, J.; Chu, J.; Huang, J. A Crucial Role of GA-Regulated Flavonol Biosynthesis in Root Growth of Arabidopsis. Mol. Plant 2019, 12, 521-537. [CrossRef] [PubMed]

68. Zhang, X.; He, Y.; Li, L.; Liu, H.; Hong, G. Involvement of the R2R3-MYB transcription factor MYB21 and its homologs in regulating flavonol accumulation in Arabidopsis stamen. J. Exp. Bot. 2021, 72, 4319-4332. [CrossRef] [PubMed]

69. Zhi, J.J.; Liu, X.X.; Li, D.J.; Huang, Y.G.M.; Yan, S.S.; Cao, B.H.; Qiu, Z.K. CRISPR/Cas9-mediated SlAN2 mutants reveal various regulatory models of anthocyanin biosynthesis in tomato plant. Plant Cell Rep. 2020, 39, 799-809. [CrossRef]

70. Sun, C.; Deng, L.; Du, M.; Zhao, J.; Chen, Q.; Huang, T.; Jiang, H.; Li, C.B.; Li, C. A Transcriptional Network Promotes Anthocyanin Biosynthesis in Tomato Flesh. Mol. Plant 2020, 13, 42-58. [CrossRef] [PubMed]

71. Yan, S.S.; Chen, N.; Huang, Z.J.; Li, D.J.; Zhi, J.J.; Yu, B.W.; Liu, X.X.; Cao, B.H.; Qiu, Z.K. Anthocyanin Fruit encodes an R2R3-MYB transcription factor, SlAN2-like, activating the transcription of SIMYBATV to fine-tune anthocyanin content in tomato fruit. New Phytol. 2020, 225, 2048-2063. [CrossRef]

72. Fornale, S.; Lopez, E.; Salazar-Henao, J.E.; Fernandez-Nohales, P.; Rigau, J.; Caparros-Ruiz, D. AtMYB7, a New Player in the Regulation of UV-Sunscreens in Arabidopsis thaliana. Plant Cell Physiol. 2014, 55, 507-516. [CrossRef]

73. Matsui, K.; Umemura, Y.; Ohme-Takagi, M. AtMYBL2, a protein with a single MYB domain, acts as a negative regulator of anthocyanin biosynthesis in Arabidopsis. Plant J. 2008, 55, 954-967. [CrossRef]

74. Aharoni, A.; De Vos, C.H.; Wein, M.; Sun, Z.; Greco, R.; Kroon, A.; Mol, J.N.; O'Connell, A.P. The strawberry FaMYB1 transcription factor suppresses anthocyanin and flavonol accumulation in transgenic tobacco. Plant J. 2001, 28, 319-332. [CrossRef]

75. Cavallini, E.; Matus, J.T.; Finezzo, L.; Zenoni, S.; Loyola, R.; Guzzo, F.; Schlechter, R.; Ageorges, A.; Arce-Johnson, P.; Tornielli, G.B. The Phenylpropanoid Pathway Is Controlled at Different Branches by a Set of R2R3-MYB C2 Repressors in Grapevine. Plant Physiol. 2015, 167, 1448-1470. [CrossRef] [PubMed]

76. Nukumizu, Y.; Wada, T.; Tominaga-Wada, R. Tomato (Solanum lycopersicum) homologs of TRIPTYCHON (SITRY) and GLABRA3 (SlGL3) are involved in anthocyanin accumulation. Plant Signal. Behav. 2013, 8, e24575. [CrossRef] [PubMed]

77. Cao, X.; Qiu, Z.K.; Wang, X.T.; Van Giang, T.; Liu, X.L.; Wang, J.; Wang, X.X.; Gao, J.C.; Guo, Y.M.; Du, Y.C.; et al. A putative R3 MYB repressor is the candidate gene underlying atroviolacium, a locus for anthocyanin pigmentation in tomato fruit. J. Exp. Bot. 2017, 68, 5745-5758. [CrossRef] [PubMed]

78. Hiratsu, K.; Matsui, K.; Koyama, T.; Ohme-Takagi, M. Dominant repression of target genes by chimeric repressors that include the EAR motif, a repression domain, in Arabidopsis. Plant J. 2003, 34, 733-739. [CrossRef] [PubMed]

79. Zhu, H.F.; Fitzsimmons, K.; Khandelwal, A.; Kranz, R.G. CPC, a Single-Repeat R3 MYB, Is a Negative Regulator of Anthocyanin Biosynthesis in Arabidopsis. Mol. Plant 2009, 2, 790-802. [CrossRef] [PubMed]

80. Huang, Y.F.; Vialet, S.; Guiraud, J.L.; Torregrosa, L.; Bertrand, Y.; Cheynier, V.; This, P.; Terrier, N. A negative MYB regulator of proanthocyanidin accumulation, identified through expression quantitative locus mapping in the grape berry. New Phytol. 2014, 201, 795-809. [CrossRef]

81. Chen, L.H.; Hu, B.; Qin, Y.H.; Hu, G.B.; Zhao, J.T. Advance of the negative regulation of anthocyanin biosynthesis by MYB transcription factors. Plant Physiol. Biochem. 2019, 136, 178-187. [CrossRef] [PubMed]

82. LaFountain, A.M.; Yuan, Y.W. Repressors of anthocyanin biosynthesis. New Phytol. 2021, 231, 933-949. [CrossRef] [PubMed]

83. Sun, X.M.; Zhang, Z.Y.; Chen, C.; Wu, W.; Ren, N.N.; Jiang, C.H.; Yu, J.P.; Zhao, Y.; Zheng, X.M.; Yang, Q.W.; et al. The C-S-A gene system regulates hull pigmentation and reveals evolution of anthocyanin biosynthesis pathway in rice. J. Exp. Bot. 2018, 69, 1485-1498. [CrossRef] [PubMed]

84. Li, Y.Q.; Shan, X.T.; Gao, R.F.; Yang, S.; Wang, S.C.; Gao, X.; Wang, L. Two IIIf Clade-bHLHs from Freesia hybrida Play Divergent Roles in Flavonoid Biosynthesis and Trichome Formation when Ectopically Expressed in Arabidopsis. Sci. Rep. 2016, 6, 30514. [CrossRef]

85. Pires, N.; Dolan, L. Origin and Diversification of Basic-Helix-Loop-Helix Proteins in Plants. Mol. Biol. Evol. 2010, $27,862-874$. [CrossRef]

86. Heim, M.A.; Jakoby, M.; Werber, M.; Martin, C.; Weisshaar, B.; Bailey, P.C. The basic helix-loop-helix transcription factor family in plants: A genome-wide study of protein structure and functional diversity. Mol. Biol. Evol. 2003, 20, 735-747. [CrossRef]

87. Baudry, A.; Heim, M.A.; Dubreucq, B.; Caboche, M.; Weisshaar, B.; Lepiniec, L. TT2, TT8, and TTG1 synergistically specify the expression of BANYULS and proanthocyanidin biosynthesis in Arabidopsis thaliana. Plant J. 2004, 39, 366-380. [CrossRef] [PubMed] 
88. Zhang, B.P.; Chopra, D.; Schrader, A.; Hulskamp, M. Evolutionary comparison of competitive protein-complex formation of MYB, bHLH, and WDR proteins in plants. J. Exp. Bot. 2019, 70, 3197-3209. [CrossRef]

89. Spelt, C.; Quattrocchio, F.; Mol, J.N.; Koes, R. anthocyanin1 of petunia encodes a basic helix-loop-helix protein that directly activates transcription of structural anthocyanin genes. Plant Cell. 2000, 12, 1619-1632. [CrossRef]

90. Fan, Y.; Peng, J.; Wu, J.; Zhou, P.; He, R.; Allan, A.C.; Zeng, L. NtbHLH1, a JAF13-like bHLH, interacts with NtMYB6 to enhance proanthocyanidin accumulation in Chinese Narcissus. BMC Plant Biol. 2021, 21, 275. [CrossRef]

91. Montefiori, M.; Brendolise, C.; Dare, A.P.; Lin-Wang, K.; Davies, K.M.; Hellens, R.P.; Allan, A.C. In the Solanaceae, a hierarchy of bHLHs confer distinct target specificity to the anthocyanin regulatory complex. J. Exp. Bot. 2015, 66, 1427-1436. [CrossRef] [PubMed]

92. Wang, L.H.; Tang, W.; Hu, Y.W.; Zhang, Y.B.; Sun, J.Q.; Guo, X.H.; Lu, H.; Yang, Y.; Fang, C.B.; Niu, X.L.; et al. A MYB/bHLH complex regulates tissue-specific anthocyanin biosynthesis in the inner pericarp of red-centered kiwifruit Actinidia chinensis cv. Hongyang. Plant J. 2019, 99, 359-378. [CrossRef] [PubMed]

93. Zhang, B.; Schrader, A. TRANSPARENT TESTA GLABRA 1-Dependent Regulation of Flavonoid Biosynthesis. Plants 2017, 6, 65. [CrossRef] [PubMed]

94. Xu, W.J.; Grain, D.; Bobet, S.; Le Gourrierec, J.; Thevenin, J.; Kelemen, Z.; Lepiniec, L.; Dubos, C. Complexity and robustness of the flavonoid transcriptional regulatory network revealed by comprehensive analyses of MYB-bHLH-WDR complexes and their targets in Arabidopsis seed. New Phytol. 2014, 202, 132-144. [CrossRef]

95. Appelhagen, I.; Jahns, O.; Bartelniewoehner, L.; Sagasser, M.; Weisshaar, B.; Stracke, R. Leucoanthocyanidin Dioxygenase in Arabidopsis thaliana: Characterization of mutant alleles and regulation by MYB-BHLH-TTG1 transcription factor complexes. Gene 2011, 484, 61-68. [CrossRef] [PubMed]

96. Brueggemann, J.; Weisshaar, B.; Sagasser, M. A WD40-repeat gene from Malus x domestica is a functional homologue of Arabidopsis thaliana TRANSPARENT TESTA GLABRA1. Plant Cell Rep. 2010, 29, 285-294. [CrossRef]

97. Koes, R.; Verweij, W.; Quattrocchio, F. Flavonoids: A colorful model for the regulation and evolution of biochemical pathways. Trends Plant Sci. 2005, 10, 236-242. [CrossRef]

98. Ramsay, N.A.; Glover, B.J. MYB-bHLH-WD40 protein complex and the evolution of cellular diversity. Trends Plant Sci. 2005, 10, 63-70. [CrossRef]

99. An, J.P.; Zhang, X.W.; You, C.X.; Bi, S.Q.; Wang, X.F.; Hao, Y.J. MdWRKY40 promotes wounding-induced anthocyanin biosynthesis in association with MdMYB1 and undergoes MdBT2-mediated degradation. New Phytol. 2019, 224, 380-395. [CrossRef]

100. Li, S.F.; Allen, P.J.; Napoli, R.S.; Browne, R.G.; Pham, H.; Parish, R.W. MYB-bHLH-TTG1 Regulates Arabidopsis Seed Coat Biosynthesis Pathways Directly and Indirectly via Multiple Tiers of Transcription Factors. Plant Cell Physiol. 2020, 61, 1005-1018. [CrossRef]

101. Gonzalez, A.; Brown, M.; Hatlestad, G.; Akhavan, N.; Smith, T.; Hembd, A.; Moore, J.; Montes, D.; Mosley, T.; Resendez, J.; et al. TTG2 controls the developmental regulation of seed coat tannins in Arabidopsis by regulating vacuolar transport steps in the proanthocyanidin pathway. Dev. Biol. 2016, 419, 54-63. [CrossRef]

102. Mao, Z.; Jiang, H.; Wang, S.; Wang, Y.; Yu, L.; Zou, Q.; Liu, W.; Jiang, S.; Wang, N.; Zhang, Z.; et al. The MdHY5-MdWRKY41MdMYB transcription factor cascade regulates the anthocyanin and proanthocyanidin biosynthesis in red-fleshed apple. Plant Sci. 2021, 306, 110848. [CrossRef]

103. Li, J.; Ma, N.; An, Y.Y.; Wang, L.J. FcMADS9 of fig regulates anthocyanin biosynthesis. Sci. Hortic. 2021, 278, 109820. [CrossRef]

104. Vrebalov, J.; Ruezinsky, D.; Padmanabhan, V.; White, R.; Medrano, D.; Drake, R.; Schuch, W.; Giovannoni, J. A MADS-box gene necessary for fruit ripening at the tomato ripening-inhibitor (rin) locus. Science 2002, 296, 343-346. [CrossRef]

105. Feng, X.; An, Y.; Zheng, J.; Sun, M.; Wang, L. Proteomics and SSH Analyses of ALA-Promoted Fruit Coloration and Evidence for the Involvement of a MADS-Box Gene, MdMADS1. Front. Plant Sci. 2016, 7, 1615. [CrossRef] [PubMed]

106. Ireland, H.S.; Yao, J.L.; Tomes, S.; Sutherland, P.W.; Nieuwenhuizen, N.; Gunaseelan, K.; Winz, R.A.; David, K.M.; Schaffer, R.J. Apple SEPALLATA1/2-like genes control fruit flesh development and ripening. Plant J. 2013, 73, 1044-1056. [CrossRef]

107. Merzlyak, M.N.; Chivkunova, O.B. Light-stress-induced pigment changes and evidence for anthocyanin photoprotection in apples. J. Photochem. Photobiol. B 2000, 55, 155-163. [CrossRef]

108. Paik, I.; Huq, E. Plant photoreceptors: Multi-functional sensory proteins and their signaling networks. Semin. Cell Dev. Biol. 2019, 92, 114-121. [CrossRef]

109. Plunkett, B.J.; Henry-Kirk, R.; Friend, A.; Diack, R.; Helbig, S.; Mouhu, K.; Tomes, S.; Dare, A.P.; Espley, R.V.; Putterill, J.; et al. Apple B-box factors regulate light-responsive anthocyanin biosynthesis genes. Sci. Rep. 2019, 9, 17762. [CrossRef]

110. An, J.P.; Liu, Y.J.; Zhang, X.W.; Bi, S.Q.; Wang, X.F.; You, C.X.; Hao, Y.J. Dynamic regulation of anthocyanin biosynthesis at different light intensities by the BT2-TCP46-MYB1 module in apple. J. Exp. Bot. 2020, 71, 3094-3109. [CrossRef] [PubMed]

111. Bai, S.; Tao, R.; Tang, Y.; Yin, L.; Ma, Y.; Ni, J.; Yan, X.; Yang, Q.; Wu, Z.; Zeng, Y.; et al. BBX16, a B-box protein, positively regulates light-induced anthocyanin accumulation by activating MYB10 in red pear. Plant Biotechnol. J. 2019, 17, 1985-1997. [CrossRef]

112. Tao, R.; Bai, S.; Ni, J.; Yang, Q.; Zhao, Y.; Teng, Y. The blue light signal transduction pathway is involved in anthocyanin accumulation in 'Red Zaosu' pear. Planta 2018, 248, 37-48. [CrossRef]

113. Ma, A.; Wang, D.; Lu, H.; Wang, H.; Qin, Y.; Hu, G.; Zhao, J. LcCOP1 and LcHY5 control the suppression and induction of anthocyanin accumulation in bagging and debagging litchi fruit pericarp. Sci. Hortic. 2021, 287, 110281. [CrossRef] 
114. Ma, Z.H.; Li, W.F.; Mao, J.; Li, W.; Zuo, C.W.; Zhao, X.; Dawuda, M.M.; Shi, X.Y.; Chen, B.H. Synthesis of light-inducible and light-independent anthocyanins regulated by specific genes in grape 'Marselan' (V. vinifera L.). Peerj 2019, 7, e6521. [CrossRef] [PubMed]

115. Lu, X.D.; Zhou, C.M.; Xu, P.B.; Luo, Q.; Lian, H.L.; Yang, H.Q. Red-light-dependent interaction of phyB with SPA1 promotes COP1-SPA1 dissociation and photomorphogenic development in Arabidopsis. Mol. Plant 2015, 8, 467-478. [CrossRef] [PubMed]

116. Sheerin, D.J.; Menon, C.; zur Oven-Krockhaus, S.; Enderle, B.; Zhu, L.; Johnen, P.; Schleifenbaum, F.; Stierhof, Y.D.; Huq, E.; Hiltbrunner, A. Light-activated phytochrome A and B interact with members of the SPA family to promote photomorphogenesis in Arabidopsis by reorganizing the COP1/SPA complex. Plant Cell 2015, 27, 189-201. [CrossRef] [PubMed]

117. Subramanian, C.; Kim, B.H.; Lyssenko, N.N.; Xu, X.; Johnson, C.H.; von Arnim, A.G. The Arabidopsis repressor of light signaling, COP1, is regulated by nuclear exclusion: Mutational analysis by bioluminescence resonance energy transfer. Proc. Natl. Acad. Sci. USA 2004, 101, 6798-6802. [CrossRef] [PubMed]

118. Wang, Q.; Lin, C. Mechanisms of Cryptochrome-Mediated Photoresponses in Plants. Annu. Rev. Plant Biol. 2020, 71, 103-129. [CrossRef]

119. Liu, B.; Zuo, Z.; Liu, H.; Liu, X.; Lin, C. Arabidopsis cryptochrome 1 interacts with SPA1 to suppress COP1 activity in response to blue light. Genes Dev. 2011, 25, 1029-1034. [CrossRef]

120. Rizzini, L.; Favory, J.J.; Cloix, C.; Faggionato, D.; O’Hara, A.; Kaiserli, E.; Baumeister, R.; Schafer, E.; Nagy, F.; Jenkins, G.I.; et al. Perception of UV-B by the Arabidopsis UVR8 protein. Science 2011, 332, 103-106. [CrossRef]

121. Cloix, C.; Kaiserli, E.; Heilmann, M.; Baxter, K.J.; Brown, B.A.; O’Hara, A.; Smith, B.O.; Christie, J.M.; Jenkins, G.I. C-terminal region of the UV-B photoreceptor UVR8 initiates signaling through interaction with the COP1 protein. Proc. Natl. Acad. Sci. USA 2012, 109, 16366-16370. [CrossRef] [PubMed]

122. Huang, X.; Ouyang, X.; Yang, P.; Lau, O.S.; Chen, L.; Wei, N.; Deng, X.W. Conversion from CUL4-based COP1-SPA E3 apparatus to UVR8-COP1-SPA complexes underlies a distinct biochemical function of COP1 under UV-B. Proc. Natl. Acad. Sci. USA 2013, 110, 16669-16674. [CrossRef]

123. Fernandes de Oliveira, A.; Mercenaro, L.; Del Caro, A.; Pretti, L.; Nieddu, G. Distinctive anthocyanin accumulation responses to temperature and natural UV radiation of two field-grown (Vitis vinifera L.) cultivars. Molecules 2015, 20, 2061-2080. [CrossRef] [PubMed]

124. Blancquaert, E.H.; Oberholster, A.; Ricardo-da-Silva, J.M.; Deloire, A.J. Grape Flavonoid Evolution and Composition Under Altered Light and Temperature Conditions in Cabernet Sauvignon (Vitis vinifera L.). Front. Plant Sci. 2019, 10, 1062. [CrossRef]

125. Pinasseau, L.; Vallverdu-Queralt, A.; Verbaere, A.; Roques, M.; Meudec, E.; Le Cunff, L.; Peros, J.P.; Ageorges, A.; Sommerer, N.; Boulet, J.C.; et al. Cultivar Diversity of Grape Skin Polyphenol Composition and Changes in Response to Drought Investigated by LC-MS Based Metabolomics. Front. Plant Sci. 2017, 8, 1826. [CrossRef] [PubMed]

126. Osterlund, M.T.; Hardtke, C.S.; Wei, N.; Deng, X.W. Targeted destabilization of HY5 during light-regulated development of Arabidopsis. Nature 2000, 405, 462-466. [CrossRef]

127. Shin, D.H.; Choi, M.; Kim, K.; Bang, G.; Cho, M.; Choi, S.B.; Choi, G.; Park, Y.I. HY5 regulates anthocyanin biosynthesis by inducing the transcriptional activation of the MYB75/PAP1 transcription factor in Arabidopsis. FEBS Lett. 2013, 587, $1543-1547$. [CrossRef]

128. Abbas, N.; Maurya, J.P.; Senapati, D.; Gangappa, S.N.; Chattopadhyay, S. Arabidopsis CAM7 and HY5 Physically Interact and Directly Bind to the HY5 Promoter to Regulate Its Expression and Thereby Promote Photomorphogenesis. Plant Cell 2014, 26, 1036-1052. [CrossRef]

129. Guo, X.; Wang, Y.T.; Zhai, Z.F.; Huang, T.J.; Zhao, D.; Peng, X.; Feng, C.; Xiao, Y.H.; Li, T.H. Transcriptomic analysis of light-dependent anthocyanin accumulation in bicolored cherry fruits. Plant Physiol. Biochem. 2018, 130, 663-677. [CrossRef]

130. Li, T.; Yamane, H.; Tao, R. Preharvest long-term exposure to UV-B radiation promotes fruit ripening and modifies stage-specific anthocyanin metabolism in highbush blueberry. Hortic. Res. 2021, 8, 67. [CrossRef]

131. Bhatnagar, A.; Singh, S.; Khurana, J.P.; Burman, N. HY5-COP1: The central module of light signaling pathway. J. Plant Biochem. Biotechnol. 2020, 29, 590-610. [CrossRef]

132. Bai, S.L.; Tao, R.Y.; Yin, L.; Ni, J.B.; Yang, Q.S.; Yan, X.H.; Yang, F.P.; Guo, X.P.; Li, H.X.; Teng, Y.W. Two B-box proteins, PpBBX18 and PpBBX21, antagonistically regulate anthocyanin biosynthesis via competitive association with Pyrus pyrifolia ELONGATED HYPOCOTYL 5 in the peel of pear fruit. Plant J. 2019, 100, 1208-1223. [CrossRef] [PubMed]

133. An, J.P.; Wang, X.F.; Zhang, X.W.; Bi, S.Q.; You, C.X.; Hao, Y.J. MdBBX22 regulates UV-B-induced anthocyanin biosynthesis through regulating the function of MdHY5 and is targeted by MdBT2 for $26 \mathrm{~S}$ proteasome-mediated degradation. Plant Biotechnol. J. 2019, 17, 2231-2233. [CrossRef] [PubMed]

134. Samkumar, A.; Jones, D.; Karppinen, K.; Dare, A.P.; Sipari, N.; Espley, R.V.; Martinussen, I.; Jaakola, L. Red and blue light treatments of ripening bilberry fruits reveal differences in signalling through abscisic acid-regulated anthocyanin biosynthesis. Plant Cell Environ. 2021, 44, 3227-3245. [CrossRef] [PubMed]

135. Zhang, Y.; Hu, W.; Peng, X.; Sun, B.; Wang, X.; Tang, H. Characterization of anthocyanin and proanthocyanidin biosynthesis in two strawberry genotypes during fruit development in response to different light qualities. J. Photochem. Photobiol. B 2018, 186, 225-231. [CrossRef] [PubMed] 
136. Qiu, Z.K.; Wang, H.J.; Li, D.J.; Yu, B.W.; Hui, Q.L.; Yan, S.S.; Huang, Z.J.; Cui, X.; Cao, B.H. Identification of Candidate HY5-Dependent and -Independent Regulators of Anthocyanin Biosynthesis in Tomato. Plant Cell Physiol. 2019, 60, 643-656. [CrossRef]

137. D’Amelia, V.; Villano, C.; Batelli, G.; Cobanoglu, O.; Carucci, F.; Melito, S.; Chessa, M.; Chiaiese, P.; Aversano, R.; Carputo, D. Genetic and epigenetic dynamics affecting anthocyanin biosynthesis in potato cell culture. Plant Sci. 2020, 298, 110597. [CrossRef] [PubMed] 